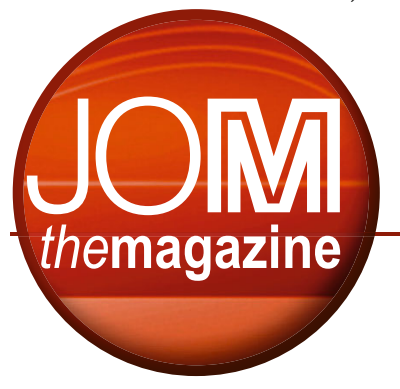

\title{
TMS2016 Proceedings Volumes Available for Purchase
}

TMS 2016 Annual

Meeting \& Exhibition

(TMS2016) registrants

have free, online

access to the

meeting's collected

proceedings as a

benefit of attending.

If you couldn't make

the meeting, you

can still access all

published papers by

purchasing TMS2016

proceedings volumes,

available through

TMS's publishing

partner, John Wiley

\& Sons, at

www.wiley.com.

\section{TMS content update}

Look for news and updates on TMS journals, publications, and online resources, as well as opportunities for editors and authors, in this regular JOM feature.

\section{7th International Symposium on High-Temperature Metallurgical}

\section{Processing}

Editors: Jiann-Yang Hwang, Tao Jiang, P. Chris Pistorius, Gerardo R.F. Alvear F.,

Onuralp Yücel, Liyuan Cai, Baojun Zhao, Dean Gregurek, Varadarajan Seshadri

Highlights advancements in new high-temperature metallurgical technologies and their applications in such areas as minerals processing; metals extraction; preparation of metallic, refractory, and ceramic materials; and treatment and recycling of slags and wastes.

\section{CFD Modeling and Simulation in Materials Processing 2016}

Editors: Laurentiu Nastac, Lifeng Zhang, Brian G. Thomas, Miaoyong Zhu, Andreas Ludwig,

Adrian S. Sabau, Hervé Combeau

Explores computational fluid dynamics (CFD) modeling and simulation of engineering

processes, to include topics such as iron and steelmaking, microstructure evolution, casting with external field interaction, smelting, degassing, mechanical mixing, and ingot casting.

\section{Characterization of Minerals, Metals, and Materials 2016}

Editors: Shadia Jamil Ikhmayies, Bowen Li, John S. Carpenter, Jiann-Yang Hwang,

Sergio Neves Monteiro, Jian Li, Donato Firrao, Mingming Zhang, Zhiwei Peng,

Juan P. Escobedo-Diaz, Chenguang Bai

Provides broad and up-to-date results in the research and development of materials characterization and processing, encompassing minerals, metals, and materials characterization and developments in extraction to the fabrication and performance of materials.

\section{Energy Technology 2016: Carbon Dioxide Management and Other Technologies}

Editors: Li Li, Donna Post Guillen, Neale Neelameggham, Lei Zhang, Jingxi Zhu, Xuan Liu, Soumendra N. Basu, Nawshad Haque, Tao Wang, Dirk E. Verhulst, Amit Pandey

Addresses the issues, complexities, and challenges related to mass and energy flow in the chemical and process engineering industry by providing focused scientific information and accessible resources on sustainable technologies with reduced energy consumption and pollutants.
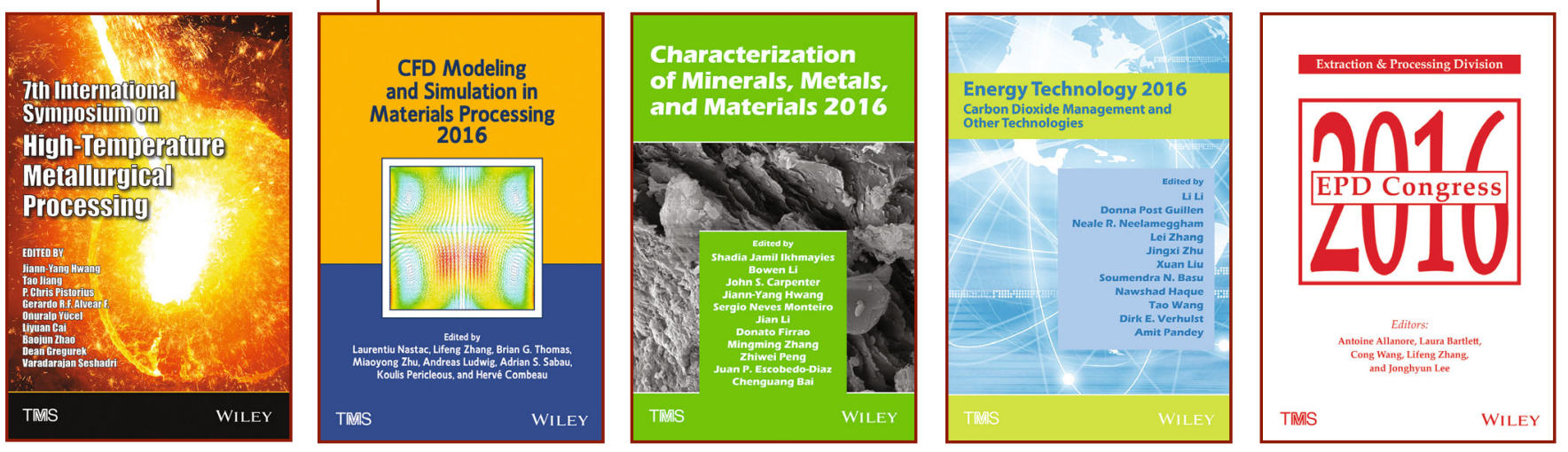


\section{EPD Congress 2016}

Editors: Antoine Allanore, Laura Bartlett, Cong Wang, Lifeng Zhang, Jonghyun Lee

Compiles papers from one of the largest yearly gatherings of extraction specialists in the world, covering many aspects of extraction and processing metallurgy.

\section{Light Metals 2016 \\ Editor: Edward Williams}

Spotlights new research within the following topic areas: Alumina and Bauxite; Aluminum Alloys, Processing, and Characterization; Aluminum Reduction Technology; Cast Shop Technology; Electrode Technology; and Strip Casting. For more than 40 years Light Metals has been one of the most widely recognized and authoritative sources of information on new developments in aluminum production technology.

\section{Magnesium Technology 2016}

Editors: Alok Singh, Kiran Solanki, Michele V. Manuel, Neale R. Neelameggham

Summarizes research carried out globally on all aspects of magnesium, making this a "go to" volume for any literature search in the field of magnesium alloy development and application.

\section{Rare Metal Technology 2016}

Editors: Shafiq Alam, Hojong Kim, Neale R. Neelameggham, Takanari Ouchi, Harald Oosterhof

Examines new research and advancements in the extraction of rare metals, as well as rare extraction processing techniques used in metal production processing. Processing techniques covered include direct extraction process for rare earth element recovery, biosorption of precious metals, fluorination behavior of uranium and zirconium mixture of fuel debris treatment, and recovery of valuable components of commodity metals.

\section{REWAS 2016}

Editors: Randolph E. Kirchain, Bart Blanpain, Christina Meskers, Elsa Olivetti, Diran Apelian, John Howarter, Anne Kvithyld, Brajendra Mishra, Neale R. Neelameggham, Jeff Spangenberger

Explores the trends and drivers toward sustainability, as well as enabling materials technologies and evaluation tools.

\section{Shape Casting: 6th International Symposium} Editors: Murat Tiryakioğlu, Mark Jolly, Glenn Byczynski

Offers the latest updates in the science, engineering, and technology of shape castings, addressing such topics as structure-property-performance relationships, modeling of casting processes, and the effect of casting defects on the mechanical properties of cast alloys.

\section{TMS 2016 Supplemental Proceedings}

Presents papers from the TMS 2016 Annual Meeting \& Exhibition, encompassing a wide range of topics of value to the minerals, metals, and materials communities, from basic research to industrial application.
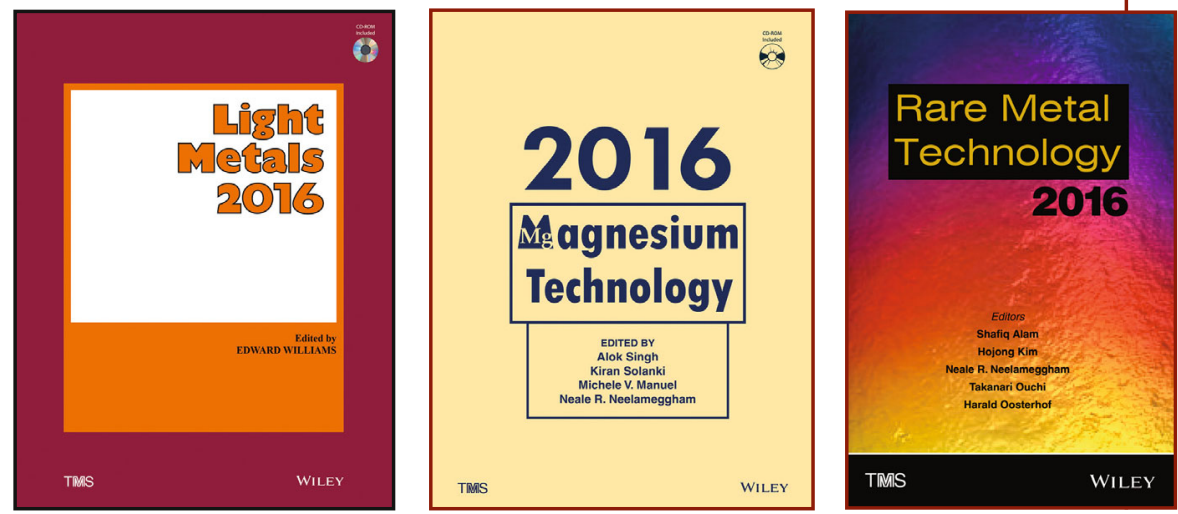

TMS members receive

a 35 percent discount

on the list price of these publications, as well as other products sold by Wiley. Access the member discount code in the TMS-Wiley

Bookstore section of the TMS Knowledge

Resource Center at knowledge.tms.org
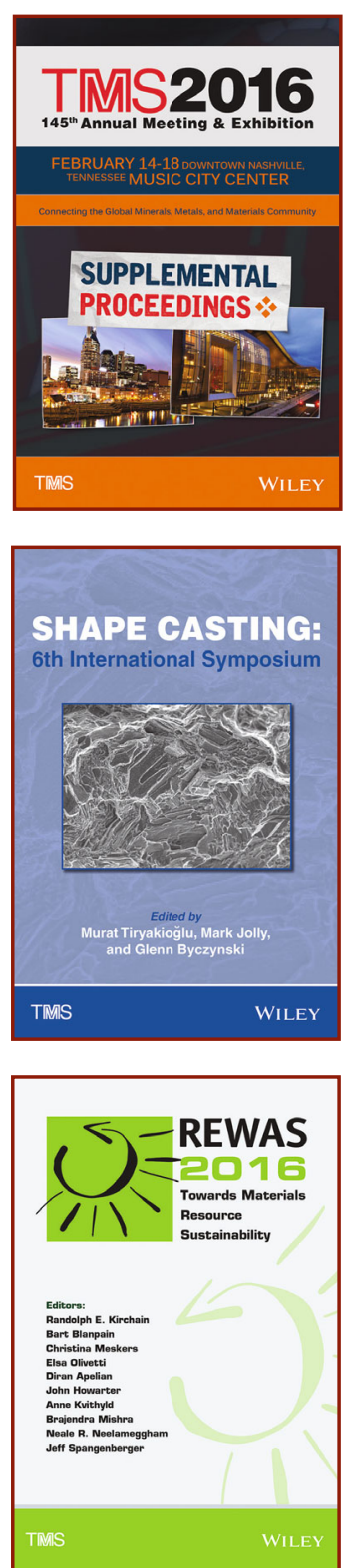